\title{
Astrocytes, Oligodendrocytes, and Schwann Cells Share a Common Antigenic Determinant That Cross-Reacts with Myelin Basic Protein: Identification with Monoclonal Antibody
}

\author{
T. Brenner, R. P. Lisak, A. Rostami, D. E. Pleasure, and D. H. Silberberg \\ Department of Neurology, School of Medicine, University of Pennsylvania and Children's Hospital of Philadelphia, \\ Philadelphia, Pennsylvania 19104
}

\begin{abstract}
We have produced a monoclonal antibody against myelin basic protein that reacts with astrocytes, oligodendrocytes, and Schwann cells. This antibody was generated by fusion of mouse myeloma cells with spleen cells from BALB/c mice immunized with delipidated white matter from adult rat corpus callosum. The antibody was characterized via solid-phase radioimmunoassay, immunoblot of SDS-PAGE, and by indirect immunofluorescence staining of monolayer cultures containing oligodendrocytes, astrocytes, and Schwann cells. Myelin basic protein (MBP) was shown previously to be present only in myelin producing cells in CNS and PNS (oligodendroglia and Schwann cells) and not in astrocytes. The binding of this monoclonal antibody to all 3 cell types suggests that these cells share a common epitope. This epitope may be related to a common progenitor cell.
\end{abstract}

Certain lipids and proteins are thought to occur mainly in myelin and its associated cells (Davison and Peters, 1970). Among the lipids are the galactospingolipids, galactocerebroside (GalC), and sulfatide, and among the proteins, myelin basic protein (MBP) and 2',3'-cyclic nucleotide-3-phosphohydrolase (CNP).

Antisera and monoclonal antibodies that react with these lipids and proteins are used as cell-type specific markers (Bignami et al., 1972; Brockes et al., 1977; Kennedy et al., 1980; Raff et al., 1978, 1979). These antisera and antibodies provide a powerful tool for the identification and the study of the differentiation of glia and neurons of the CNS and PNS.

MBP, one of the principal components of the myelin membrane (Norton and Poduslo, 1973), is expressed in oligodendrocytes in various nonmyelinating brain cell cultures (Barbarese and Pfieffer, 1981; Bologa-Sandru et al., 1981; Mirsky et al., 1980; Roussel et al., 1981; Sternberger et al., 1978), as well as in freshly isolated Schwann cells (Mirsky et al., 1980). Available data on the antigenicity of MBP and its chemical nature indicate that the amino acid sequence is highly conserved in MBP isolated from several species (Dunkley and Carnegie, 1974). However, MBP isolated from mouse or rat $\mathrm{CNS}$ is polymorphic and contains 4 forms of MBP differing in molecular weight. Nevertheless, these polymorphic forms have similar amino acid sequences and antigenic sites (Barbarese et al., 1977; Martenson et al., 1972). In the present study, we provide direct evidence that astrocytes share a common intracellular antigenic determinant with oligodendrocytes and Schwann cells that crossreacts with MBP.

\footnotetext{
Received July 22, 1985; revised Nov. 19, 1985; accepted Nov. 21, 1985.

Supported by USPHS Grant NS1 1037 and Teacher Investigator Award NS00788 (A.R.) and the National Multiple Sclerosis Society and the Penn-Israel Fund.

Correspondence should be addressed to Dr. Robert P. Lisak, Department of Neurology, Hospital of the University of Pennsylvania, 3400 Spruce Street, Philadelphia, PA 19104.

Copyright (C) 1986 Society for Neuroscience $0270-6474 / 86 / 071925-09 \$ 02.00 / 0$
}

\section{Materials and Methods}

\section{Antigen preparation}

Corpus callosum white matter from 3- to 4-week-old rats was delipidated by extracting with chloroform-methanol-water (CCE) (Norton and Poduslo, 1973). In brief, the white matter was stirred with chloroform-methanol-water $(4: 8: 3, \mathrm{vol} / \mathrm{vol} / \mathrm{vol})$ for $30 \mathrm{~min}$ at $25^{\circ} \mathrm{C}$, and then centrifuged. The precipitate was homogenized in chloroformmethanol-water and sonicated in a bath sonicator for $2 \mathrm{~min}$. The tissue was then washed $3 \times$ with the chloroform-methanol-water solution and dried under nitrogen gas.

\section{Production of hybridoma cell secreting monoclonal antibodies}

$\mathrm{BALB} / \mathrm{c}$ mice were injected intraperitoneally with $1 \mathrm{mg}$ antigen (CCE) in complete Freund's adjuvant. The mice were boosted $3 \times$ intraperitoneally with the same amount of antigen in incomplete Freund's adjuvant at 3 week intervals. Four days after the last injection, the mice were sacrificed and isolated spleen cells were fused with the nonsecreting SP2/0 mouse plasmacytoma cell line (from the Cell Center of the University of Pennsylvania), using polyethylene glycol. The hybrids were culturcd as described by Kennett et al. (1982). Supcrnatants from successful fusions were screened for their capacity to bind the CCE, other myelin antigens, and cell cultures, in a solid-phase radioimmunoassay (RIA) (see below). Positive lines were then cloned by limiting dilution. Ascitic fluid was obtained by intraperitoneal injection of BALB/c mice with $10^{7}$ hybridoma cells, 2 weeks after a priming injection of pristane.

The antibody class was determined by double-diffusion immunoprecipitation (Ouchterlony) using rabbit anti-mouse immunoglobulin antisera (Bionetics, Kensington, MD).

\section{Antigens for RIA, immunoblot, and absorption studies}

CNS and PNS myelin were prepared from adult female rats by the method of Norton and Poduslo (1973). Guinea pig MBP was prepared by the method of Deibler et al. (1972). Bovine Gal C was purchased from Sigma, and protein S-100 was a gift of Dr. Sheldon Miller (Wistar Institute). A suspension of the antigen (CCE) in $0.01 \mathrm{M}$ borate buffer $(\mathrm{pH} 8)$ was sonicated, and then SDS was added to final concentration of $0.05 \%$ when CCE was employed in the solid-phase RIA.

\section{Solid-phase RIA}

Fifty microliters of $0.01 \mathrm{M}$ borate buffer $(\mathrm{pH} 8$ ) containing the various test antigens $(20 \mu \mathrm{g})$ were placed in wells of a polyvinyl chloride microtiter plate (Dynatech Laboratories, Alexandria, VA) and dried overnight at $25^{\circ} \mathrm{C}$. Wells were incubated for $2 \mathrm{hr}$ with solution of $1 \% \mathrm{BSA}$ in $0.17 \mathrm{M}$ borate buffer, $\mathrm{pH} 8.0$, containing $0.9 \% \mathrm{NaCl}$ and $0.04 \% \mathrm{NaN}_{3}$ (borate saline buffer, BSB) to block remaining protein-binding sites in the wells. They were then washed $3 \times$ with $0.5 \%$ BSA in BSB and incubated with $50 \mu$ lof the monoclonal antibody overnight at $4^{\circ} \mathrm{C}$. Wells were then washed $3 \times$ with $0.5 \%$ BSA in BSB, $50 \mu$ l of ${ }^{125}$ I-labeled goat anti-mouse Ig (Amersham) was added and the plates covered and incubated overnight at $4^{\circ} \mathrm{C}$. Wells were subsequently washed $4 \times$ with $0.5 \% \mathrm{BSA}$ in BSB, cut from the plates, and radioactivity quantitated in a Packard gamma spectrophotometer. The control supernatants were obtained from cultures of the parent myeloma cell line SP $2 / 0$ and a 
supernatant of a mouse IgM monoclonal antibody to chicken myoblasts (gift of Dr. Alan F. Horwitz, University of Pennsylvania).

\section{RIA to cell surface and cytoplasm}

Rat oligodendrocytes (see below), dissociated brain cells from newborn rats (see below) or skin fibroblasts were plated on poly(L-lysine)-coated wells of microtiter plates $(50-100,000$ cells/well). The cells were cultured for 18-96 hr prior to usc in the RIA. The assay was performed with both living cells and after fixation with acid-alcohol as previously described (Lisak et al., 1983). In brief, $50 \mu \mathrm{l}$ of the tested hybridoma supernatants were added and incubated $90 \mathrm{~min}$ at $25^{\circ} \mathrm{C}$, after washing with additional medium, ${ }^{125}$ I-goat anti-mouse was added for $90 \mathrm{~min}$. The wells were washed twice, and then $100 \mu \mathrm{l} 1 \mathrm{~N} \mathrm{NaOH}$ was added to hydrolyze and release the cells. The mixture was transferred to tubes and the radioactivity quantitated on a Packard gamma spectrophotometer.

\section{Antisera and antigens}

Rabbit anti-GalC or rabbit anti-ovalbumin/complete Freund's adjuvant (OV/CFA) as a control was prepared as described previously (Raff et al., 1978). Rabbit anti-glial fibrillary acid protein (GFAP) was purchased from Accurate Chemical. Rabbit anti-human plasma fibronectin (FN) was purchased from Bethesda Research Laboratories, Inc. Rat antineurofilament was a gift of Dr. V. Lee (Lee et al., 1982), and rabbit anti-MBP was a gift from Dr. Sheldon Miller. We also employed monoclonal anti-MBP, which was purchased from Hybritech (San Diego, CA), and monoclonal anti- $A_{2} B_{5}$ (Eisenbarth et al., 1979) was a gift of Dr. Marshall Nirenberg.

Guinea pig MBP and calf-thymus histone were cross-linked with glutaraldehyde (Ternynck and Avrameas, 1976), followed by extensive washing with PBS. The supernatants from the cloned hybridomas were incubated for $4 \mathrm{hr}$ at $25^{\circ} \mathrm{C}$ and overnight at $4^{\circ} \mathrm{C}$ with cross-linked MBP or cross-linked calf-thymus histone. The suspensions were centrifuged at $115,000 \times g$ for $5 \mathrm{~min}$ in a Beckman air ultracentrifuge. The cleared supernatants were used for indirect immunofluorescence (IF).

\section{Indirect immunofluorescence}

Antibodies to GalC (Raff et al., 1978), GFAP (Abney et al., 1981; Raff et al., 1978), FN (Kennedy et al., 1980), and neurofilaments (Lee et al., 1982) were used to identify oligodendrocytes, astrocytes, fibroblasts, and neurons, respectively. Anti-OV/CFA (Eccleston and Silberberg, 1984) or normal rabbit serum and second antibody (see below) was used to identify macrophage-microglia (Kennedy et al., 1980; Mirsky et al., 1980). IF was performed as described previously (Eccleston and Silberberg, 1984). To test for binding to surface of living cells, cultures were incubated at room temperature with $30 \mu \mathrm{l}$ of anti-Gal C (1:100), anti-FN $(1: 30)$, or anti- $\mathrm{A}_{2} \mathrm{~B}_{5}(1: 100)$ with modified Eagle's medium (MEM) containing $10 \mathrm{~mm}$ HEPES buffer for $25 \mathrm{~min}$. After washing in MEM-HEPES, the cells were incubated for a further $25 \mathrm{~min}$ with rhodamine-conjugated (Fab) ${ }^{2}$ fragment of goat anti-rabbit IgG (Fab) ${ }^{2}$ fragment (Cappel) for anti-GalC and anti-FN or rhodamine-conjugated goat anti-mouse Ig for anti- $A_{2} B_{5}$. After additional washing cells were fixed with $5 \%$ acetic acid in ethanol (acid-alcohol) at $-20^{\circ} \mathrm{C}$ for $10 \mathrm{~min}$, washed in water, and mounted in glycerol on glass slides.

For the demonstration of GFAP and neurofilaments, cells were fixcd first with acid-alcohol. Otherwise, the procedure was the same except that for the monoclonal anti-neurofilament, fluorescein-conjugated goat anti-rat IgG (Tago) was used as second antibody.

The hybridoma supernatant was tested for both surface and cytoplasmic binding by IF, using goat anti-mouse Ig conjugated with fluorescein (FITC) as second antibody. Double-labeling experiments were carried out for unequivocal demonstration of the cell type binding monoclonal antibody (Kennedy et al., 1980; Mirsky et al., 1980; Raff et al., 1978) as described in Results.

\section{Preparation of cells}

Rat oligodendrocytes were obtained from corpus callosum of 4-weekold rats as described previously (Hirayama et al., 1983). These cells were cultured for 4-8 d prior to assay. Dissociated brain cells from newborn rats (up to $2 \mathrm{~d}$ old) were prepared and cultured as previously described (Eccleston and Silberberg, 1984) in serum-containing or serum-free media. Mouse oligodendrocytes were obtained as recently re- ported (Suzumura et al., 1984) and cultures of adult human oligodendrocytes were a gift of Dr. Sung Kim (Kim et al., 1984). Schwann cells were prepared from sciatic nerve of neonatal rats (Kreider et al., 1981). Rat astrocytes were prepared according to Kim et al. (1983).

Rat spleen cells were isolated from adult rats and concentrated on glass slides using a cytospin centrifuge prior to fixation and use for IF.

\section{Acrylamide gel electrophoresis and electrophoretic transfer of proteins in nitrocellulose}

\section{Preparation of myelin for $S D S-P A G E$}

Myelin was delipidated by extraction with chloroform-methanol (1:2). The proteins were solubilized by suspending the delipidated myelin in disrupting buffer $(0.5 \mathrm{~m}$ Tris- $\mathrm{HCl}, \mathrm{pH} 7.0$, containing $1 \% \mathrm{SDS}, 4 \%$ mercaptoethanol, and $0.025 \%$ bromophenol blue). The suspension was sonicated in a bath sonicator, boiled $5 \mathrm{~min}$, and centrifuged at $115,000 \times$ $g$ for $5 \mathrm{~min}$ in a Beckman air ultracentrifuge. The supernatant was used for SDS-PAGE. Generally, 150-250 $\mu \mathrm{g}$ of myelin protein were loaded onto each for SDS-PAGE. The protein concentration was determined by Coomassie blue method (Bradford, 1976).

\section{$S D S \cdot P A G E$}

SDS-PAGE was performed on a slab gel apparatus (Bio Rad, Richmond, CA) using $1.5 \mathrm{~mm}$ thick gel containing $10 \%$ acrylamide and employing the Laemmli buffer system (1970). The molecular standards employed $\left(M_{\mathrm{w}}\right)$ were myosin, 200,000; B-galactosidase, 116,250; phosphorylase B, 92,500; BSA 68,000; ovalbumin, 43,000; carbonic anhydrase, 30,000; and lysozyme, 14,400 . The relative molecular weights of the resolved proteins were calculated by reference to a calibration curve drawn by plotting the log molecular weight of the standard versus the distance migrated.

\section{Nitrocellulose transfer and staining}

At completion of electrophoresis, the gels were immersed in an electroblot buffer $(0.0125 \mathrm{M}$ Tris- $\mathrm{HCl} ; 0.09 \mathrm{M}$ glycine, $\mathrm{pH} 8.4 ; 20 \%$ methanol) and gently rocked for $10 \mathrm{~min}$ with several changes of the buffer to remove SDS. To electroblot, the gels were then placed on filter paper and the nitrocellulose sheet was laid on top of the gel with a second piece of filter paper covering it. They were sandwiched together between 2 Scotch Brillo pads. This assembly was positioned between 2 vertical electrophoresis grids, held in place with rubber bands, and immersed in a 3 liter electrophoresis chamber containing circulating electroblot buffer for $4 \mathrm{hr}$ at $0.25 \mathrm{~A}$. After electroblot, the nitrocellulose was incubated for $1 \mathrm{hr}$ with PBS containing 0.5\% Tween-20 and 5\% BSA. Then, the nitrocellulose was incubated with the tested hybridoma supernatant overnight at $25^{\circ} \mathrm{C}$, followed by washing for 4-5 min with PBS Tween. The second antibody that was used was goat anti-mouse Ig peroxidase conjugated (1:200) Cappel, followed by washing with PBS Tween. The color reaction was developed with $0.05 \%$ 4-chloro-1-naph-

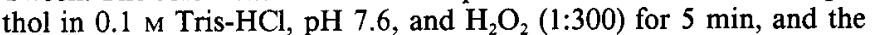
nitrocellulose strips were stored in water.

\section{Results}

\section{Screening for anti-corpus callosum (CCE) activity with RIA}

Among the 480 wells initially seeded, 144 contained viable hybridomas. Supernatants from all of these were tested in solidphase RIA for anti-CCE activity. Twenty-eight hybrid supernatants exhibited significant binding to CCE $(3 \times$ binding of control supernatants). These supernatants were also screened for anti-MBP and anti-oligodendrocyte activity by RIA and IF. Of these, 1 reacted with MBP, 7 with oligodendrocytes, and several with other cell types. We report here on one monoclonal antibody, M6C5, that reacted with MBP. This antibody exhibited significant binding in the solid-phase RIA system to CCE, MBP, CNS myelin, PNS myelin, fixed oligodendrocytes, and astrocytc cultures. It did not bind to $\mathrm{GalC}$, protein $\mathrm{S}-100$, skin fibroblasts, or the surface (live cells) of oligodendrocytes or astrocytes. This antibody reacted with rabbit anti-mouse $\operatorname{IgM}$ in Ouchterlony immunodiffusion. 

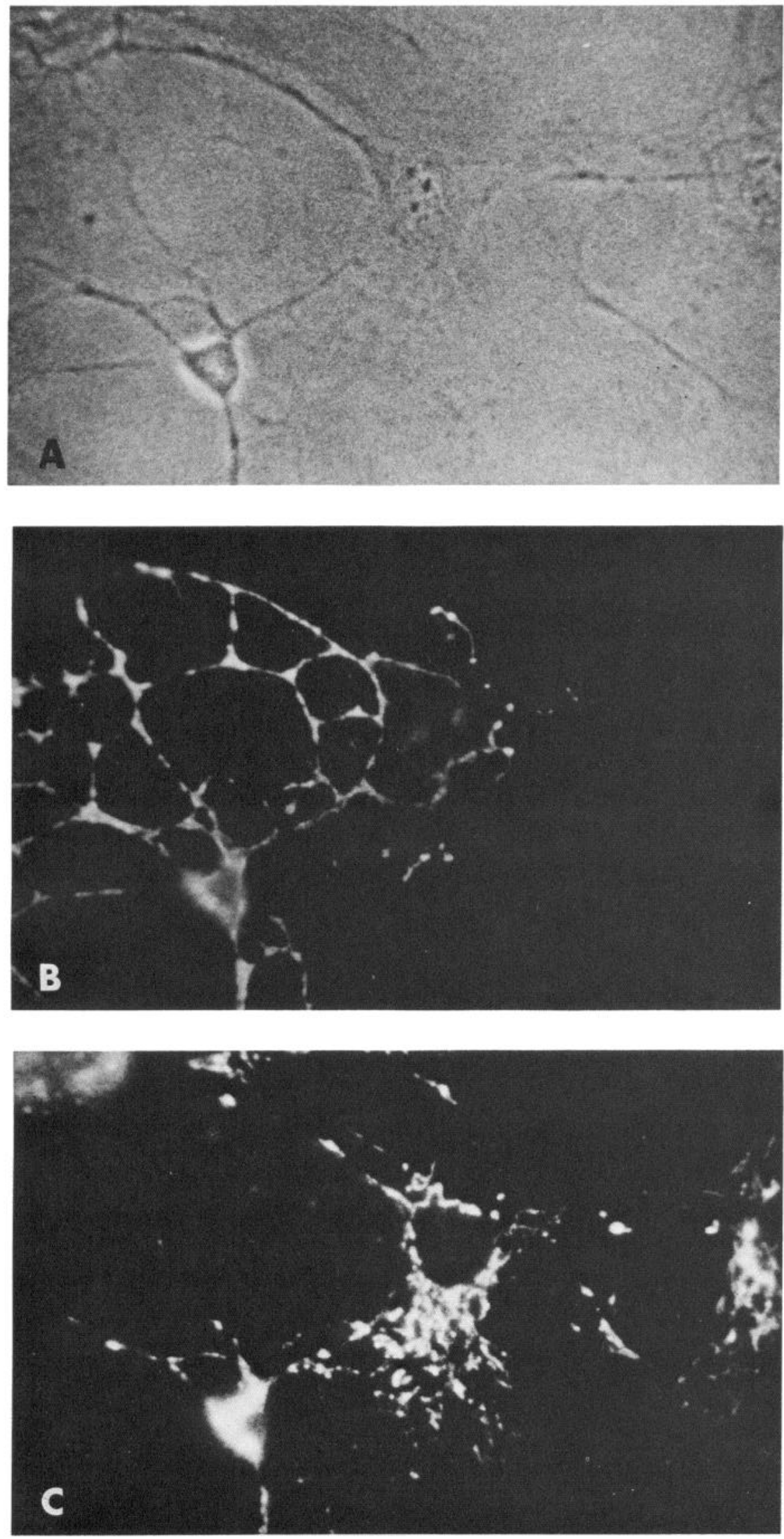

Figure 1. Diffuse binding of M6C5 antibody to oligodendrocytes. Dissociated brain cells from a newborn rat were cultured for $4 \mathrm{~d}$ in vitro, incubated with rabbit anti-galactocerebroside (R-anti-GalC) and goat antirabbit Ig-rhodamine (G-anti-R-Ig$\mathrm{Rd}$ ), fixed, and then incubated with mouse M6C5 and goat anti-mouseIg-fluorescein (G-anti-M-Ig-Fl). Cells were examined with $(A)$ phase, $(B)$ rhodamine, and $(C)$ fluorescein optics. The small process-bearing cell in the lower left that is $\mathrm{GalC}^{+}$binds $\mathrm{M} 6 \mathrm{C} 5$ in a diffuse (homogeneous) pattern. The larger flat cell surrounded by the $\mathrm{GalC}^{+}$cell processes and a second flat cell bind M6C5 in a discontinuous pattern. The flat cells are most likely astrocytes. 

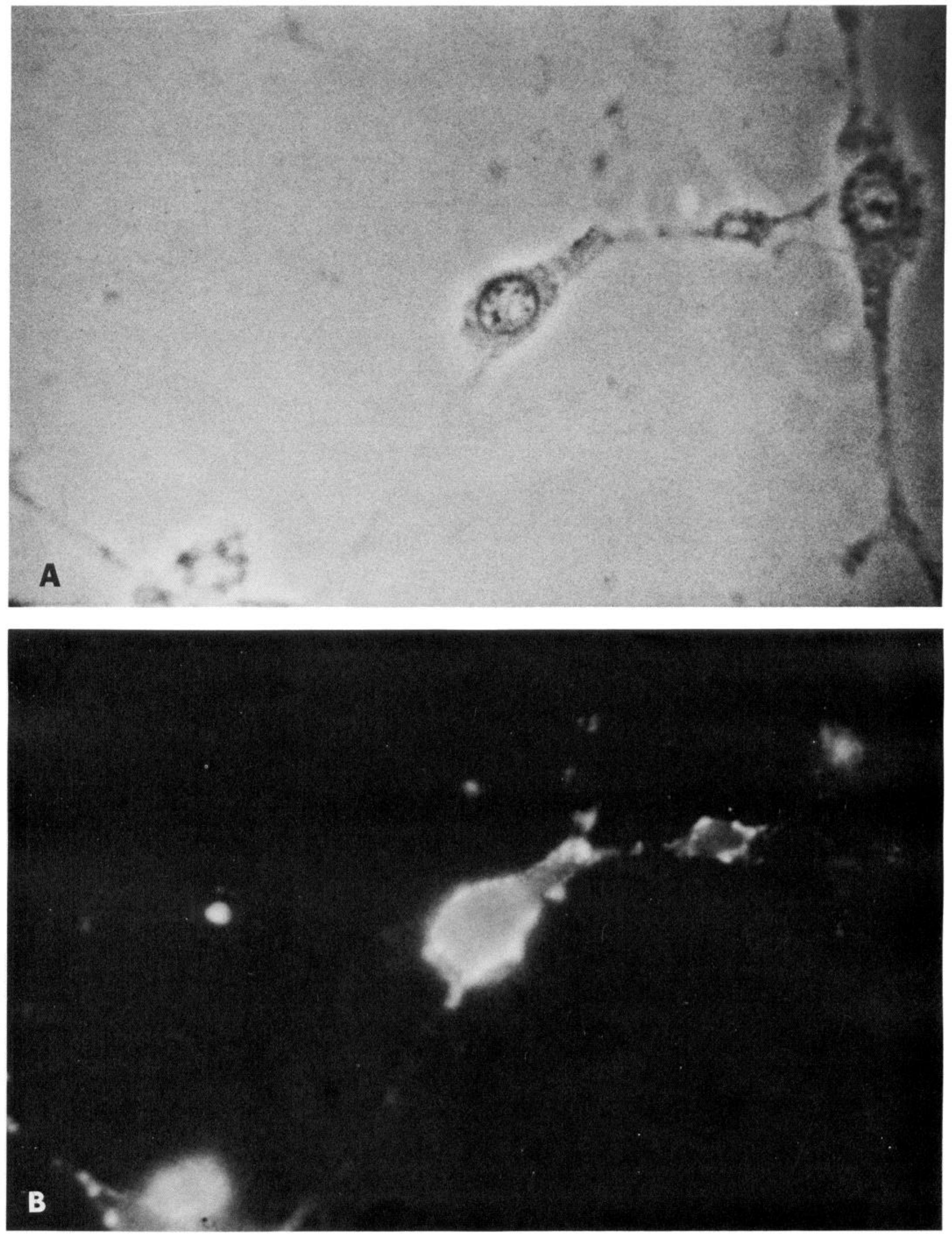


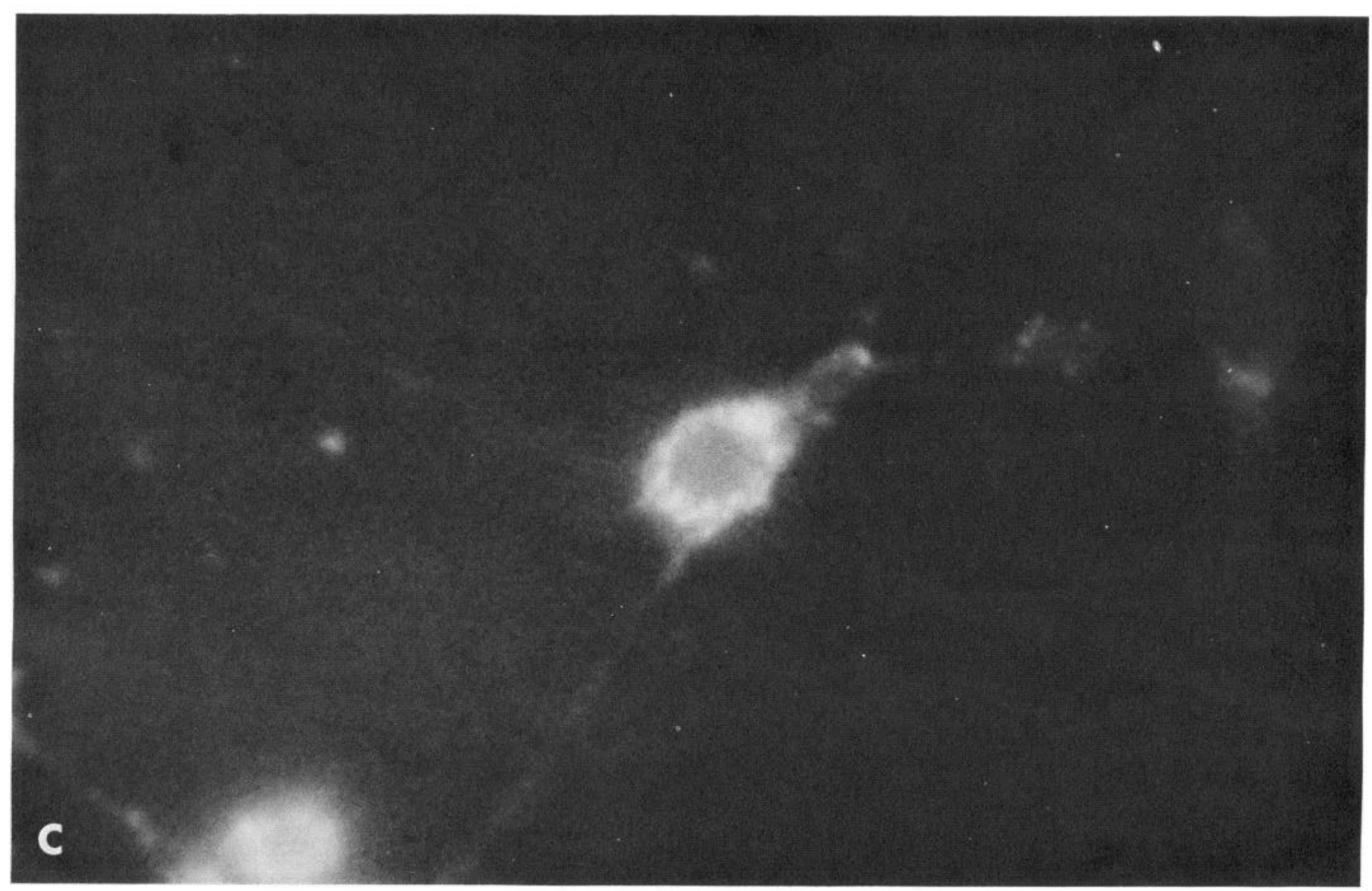

Figure 2. Discontinuous binding of M6C5 antibody to oligodendrocytes. Cultures enriched for oligodendrocytes from 4-week-old rats were maintained $4 \mathrm{~d}$ in vitro, incubated with R-anti-GalC and G-anti-R-Ig-Rd, fixed, and incubated with mouse M6C5 and G-anti-M-Ig-Fl. Cells were examined with $(A)$ phase, $(B)$ rhodamine, and $(C)$ fluorescein optics. The $\mathrm{GalC}^{+}$cell in the center of the field binds M6C5 in a discontinuous pattern.

\section{Indirect immunofluorescence studies of M6C5 binding of cultured oligodendrocytes, astrocytes, and Schwann cells}

\section{Oligodendrocytes}

The IF assays using isolated oligodendrocyte cultures from neonatal rat corpus callosum, maintained in vitro for $2-5 \mathrm{~d}$, demonstrated that monoclonal antibody M6C5 bound to the perikaryon cytoplasm of the majority of the cells in a homogeneous or diffuse pattern (Fig. 1). The same diffuse pattern was observed when polyclonal rabbit anti-MBP or the commercially available monoclonal anti-MBP were used, although fewer cells were labeled. Double-labeling of such cultures with rabbit anti-GalC and the monoclonal antibody M6C5 resulted in a coincident labeling of both GalC and M6C5 in $99 \%$ of the cells (Fig. 1). Some round cells, including anti-GalC ${ }^{+}$and anti- $\mathrm{A}_{2} \mathrm{~B}_{5}{ }^{+}$cells, showed a less homogenous intermittent pattern of binding with M6C5 (Fig. 2). In dissociated brain cultures from a $17 \mathrm{~d}$ in utero fetus or newborn rats, 2-10 d in culture, the same immunofluorescent staining pattern was observed in the oligodendrocytes, i.e., all the $\mathrm{GalC}^{+}$cells were $\mathrm{M} 6 \mathrm{C5}^{+}$. M6C5 also bound to mouse and human oligodendrocytes.

\section{Astrocytes}

Astrocytes from astrocyte-enriched cultures-from dissociated brain cultures, or as contaminants in isolated oligodendrocyte cultures-were also labeled by M6C5 in immunofluorescence assays. The astrocyte staining had a unique and characteristic pattern, which to our knowledge has not been previously described. It consists of discontinuous rodlike staining along the intracellular filaments (Fig. 1). This pattern was observed in astroyctes with both fibroblastic (Fig. 1) and protoplasmic (Fig. 3) configurations. In double-label experiments of the above cultures using the monoclonal antibody M6C5 and rabbit antiGFAP antiserum, the staining patterns observed with M6C5 and GFAP were coincidently observed within the same cells (Fig. 3).

In dissociated brain cultures and enriched astrocyte cultures, M6C5 stainings were not uniformly distributed in all fields examined. Several areas were observed in which all astrocytes were essentially positively labeled; there were also some areas in which they were negative. In the majority of the fields, $60 \%$ of the astrocytes were positive for both GFAP and M6C5; the remainder were positive for GFAP only and negative for M6C5. The labeling order was changed in order to ascertain whether anti-GFAP and M6C5 interfere with the binding of the other antibody. GFAP was added first, followed by M6C5; or reversing the staining sequence, i.e., M6C5 followed by GFAP. Identical results were obtained with both procedures. The majority of astrocytes present in cultures enriched for oligodendrocytes from 4-week-old rat corpus callosum, and maintained in vitro for 3-5 d, were stained with M6C5. Rabbit anti-MBP and commercial monoclonal mouse anti-MBP did not bind to astrocytes $\left(\mathrm{GFAP}^{+}\right.$cells). 

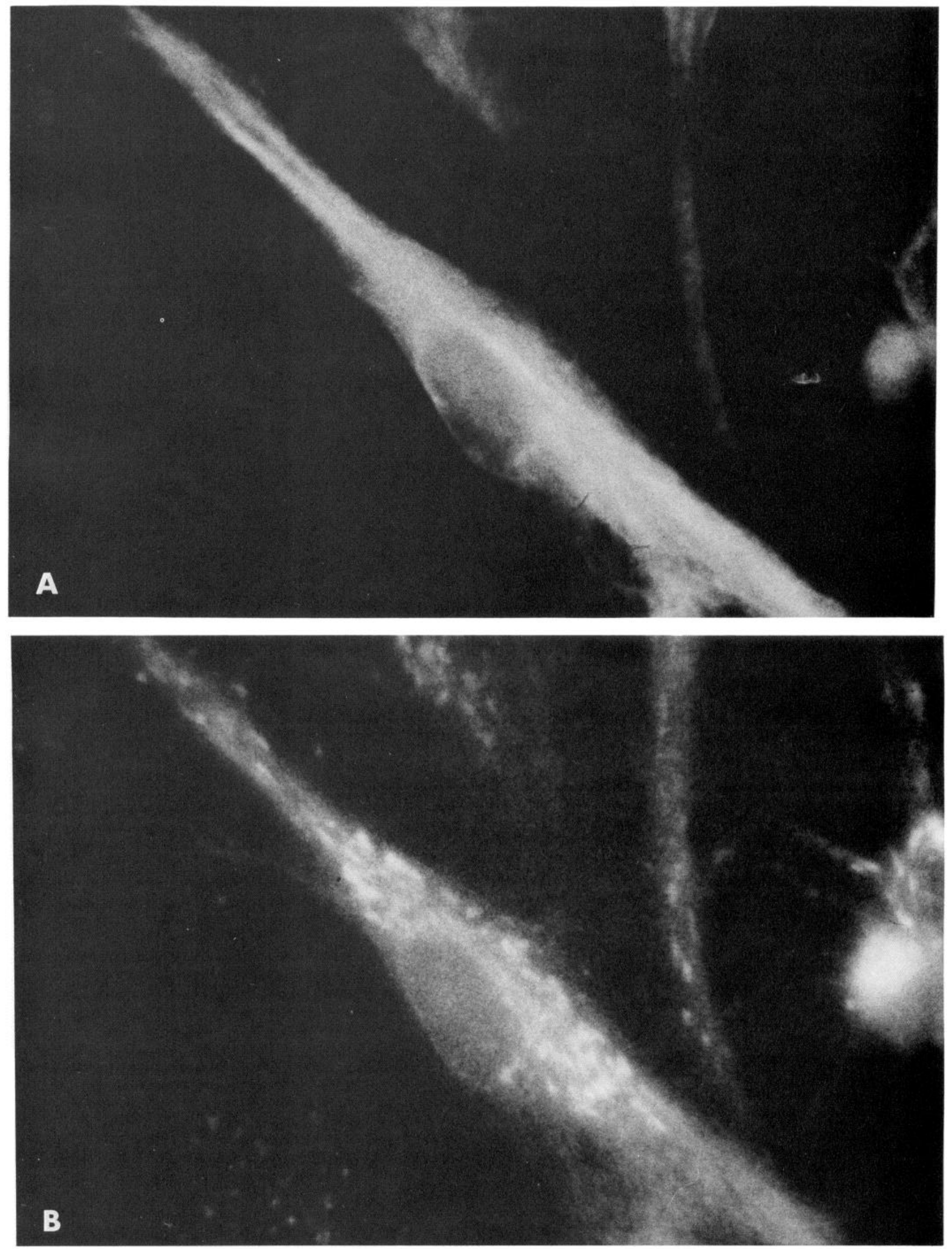


\section{Schwann cells}

Schwann cells were tested for binding of M6C5 in culture at 24, 48 , and $72 \mathrm{hr}$ in vitro. The highest percentage of positive labeling and the maximum fluorescent intensity were obtained after a period of $24 \mathrm{hr}$.

\section{Other cell types}

No binding of M6C5 to neurons (anti-neurofilament ${ }^{+}$cells), fibroblasts or meningeal cells (fibronectin ${ }^{+}$), or spleen cells was observed.

\section{Absorption studies}

Absorption of M6C5 by cross-linked MBP resulted in significantly decreased fluorescence intensity in the oligodendrocytes and astrocytes, from $4+(0-4$ scale of intensity) with the nonabsorbed supernatant to 1-2+ with absorbed antibodies. In addition, the number of stained cells decreased significantly. Supernatants absorbed with cross-linked calf-thymus histone showed no decrease in intensity of fluorescence or number of cells positive for $\mathrm{M} 6 \mathrm{C} 5$.

\section{Binding of M6C5 to CNS and PNS myelin proteins separated by SDS-PAGE}

Indirect immunofluorescence showed that the monoclonal antiMBP M6C5 recognized a determinant present in the oligodendrocytes, astrocytes, and Schwann cells. In order to establish which protein bound this antibody, we electrophoresed CCE, rat CNS myelin, rat PNS myelin, and isolated guinea pig MBP on SDS-PAGE and transferred the products to nitrocellulose. the M6C5 bound to proteins with molecular weights of 22,000 , $18,500,17,000$, and 14,000 in rat material (Fig. 4) and to a single band of $18,500 \mathrm{M}_{\mathrm{w}}$ with GP MBP (Fig. 5). In some gels of rat CNS myelin or CCE, M6C5 also bound to 2-4 proteins with molecular weights of $32,000-40,000$. No binding to any of these proteins was noted with supernatant from the parent cell line (SP 2/0) or an IgM mouse monoclonal antibody raised against chicken myoblasts (Fig. 5).

\section{Discussion}

A monoclonal anti-MBP (M6C5) was produced by immunizing mice with rat delipidated corpus callosum and fusing their spleen cells with a mouse myeloma cell line. A stable hybridoma cell line was isolated that secretes an IgM antibody that reacts with cytoplasm and not the surface of astrocytes, oligodendrocytes, and Schwann cells in RIA and immunofluorescence assays. Neurons, fibroblasts, macrophage-microglia, and lymphocytes were not labeled by this antibody. Binding was demonstrated to rat, mouse, and human cells by immunofluorescence and to rat and guinea pig by immunoblot. M6C5 was able to recognize the microheterogeneity of rat CNS MBP. The nature of the higher molecular weight bands seen occasionally is not known but may be identical to those reported by others (Carson et al., 1980; Sternberger et al., 1985).

The binding of M6C5 to astrocytes, in addition to the expected oligodendroglia and Schwann cells, suggests that these cells share a common, or at least a closely related, epitope that cross-reacts with MBP. It has been reported that oligodendrocytes and some astrocytes arise from the same precursor cell in vitro and in vivo (Raff et al., 1983a, b; Temple and Raff, 1985). Alternatively, astrocytes could also contain MBP itself, perhaps phagocytosed from myelin released during isolation or culture. However, only

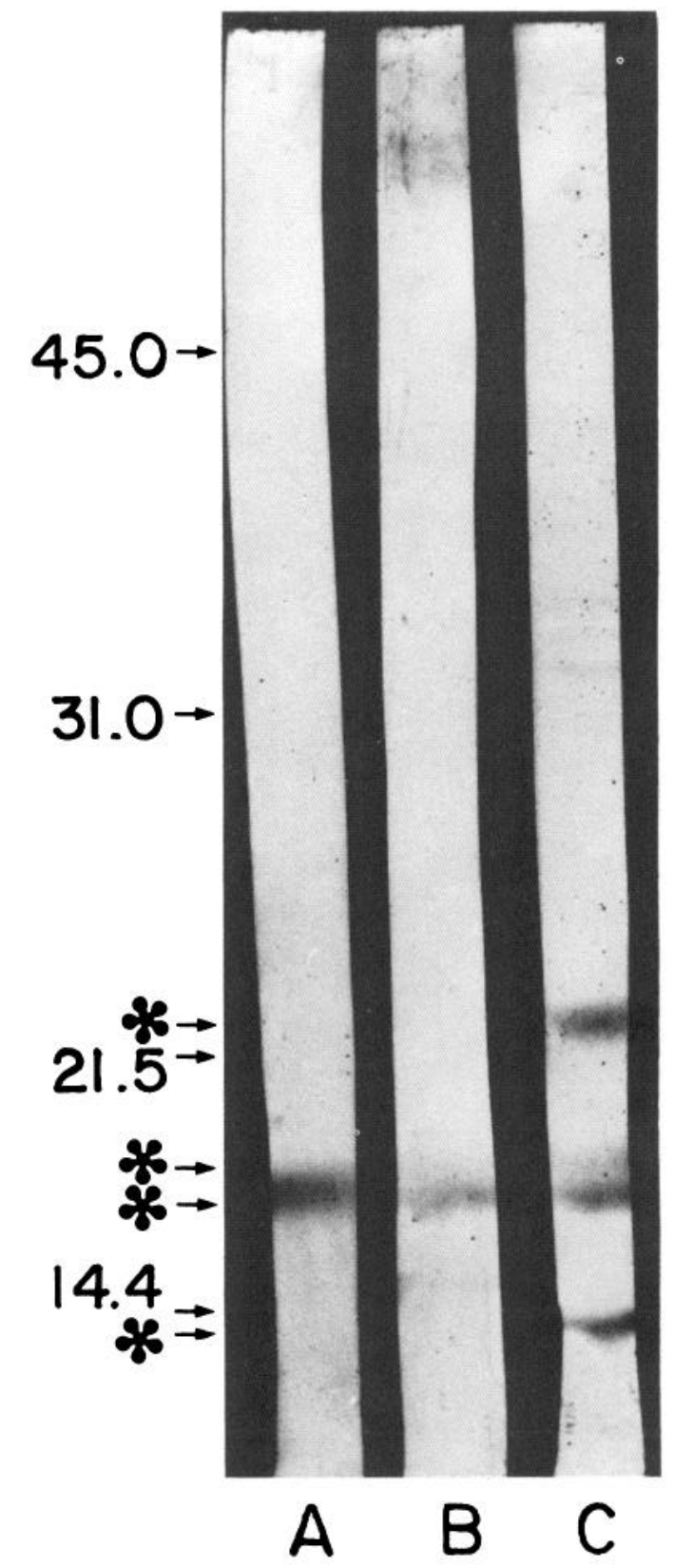

Figure 4. Nitrocellulose electroblot identification of binding by monoclonal antibody M6C5 guinea pig myelin basic protein $(10 \mu \mathrm{g}$; lane A), rat PNS myelin $(250 \mu \mathrm{g}$; lane B), and rat CNS myelin $(250 \mu \mathrm{g}$; lane $C)$ were subjected to SDS-PAGE (10\% acrylamide) and transferred onto nitrocellulose. All lanes were incubated with M6C5 followed by peroxidase staining as described in Materials and Methods. A single band at $18,500 M_{\mathrm{w}}$ is identified in lanes $A$ and $B$. Four bands are identified in lane $C(14,000,17,000,18,500$, and 22,000$)$. In addition, 3 heavier molecular weight proteins $(32,000-40,000)$ were sometimes seen only with CNS myelin or corpus callosum extract.

M6C5 bound to astrocytes, oligodendrocytes, and Schwann cells, whereas another monoclonal (commercial) anti-MBP antibody and rabbit anti-MBP bound oligodendrocytes and Schwann cells but not astrocytes. Lack of binding to astrocytes by polyclonal

\footnotetext{
Figure 3. Discontinuous binding of M6C5 antibody to astrocytes. Astrocyte-enriched cultures were obtained from newborn rat brain and maintained in vitro for $6 \mathrm{~d}$. Cells were fixed and incubated with mouse M6C5 and G-anti-M-Ig-Fl, followed by rabbit anti-glial fibrillary proteins (GFAP) and G-anti-R-Ig-Rd. The GFAP ${ }^{+}$cell in the center of the field $(A)$ and processes from other GFAP ${ }^{+}$cells bind M6C5 $(B)$ in a discontinuous pattern.

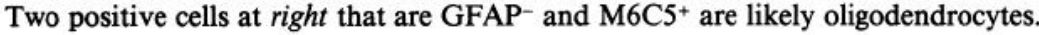


Figure 5. Nitrocellulose electroblot identification of binding by monoclonal antibody M6C5. Rat CNS myelin $(250 \mu \mathrm{g}$; lanes $A, C$, and $E)$ and rat PNS myelin ( $250 \mu \mathrm{g}$; lanes $B$, $D$, and $F$ ) were subjected to SDSPAGE (10\% acrylamide) and transferred onto nitrocellulose with supernatants of M6C5 in lanes $A$ and $B$; in lanes $C$ and $D$ of SP2/0 parent line and lanes $E$ and $F$ with supernatant of monoclonal antibody to chick myoblasts, followed by peroxidase staining as described in Materials and Methods. M6C5, but not the other supernatants, identifies an $18,500 M_{\mathrm{w}}$ problem in CNS and PNS myelin.

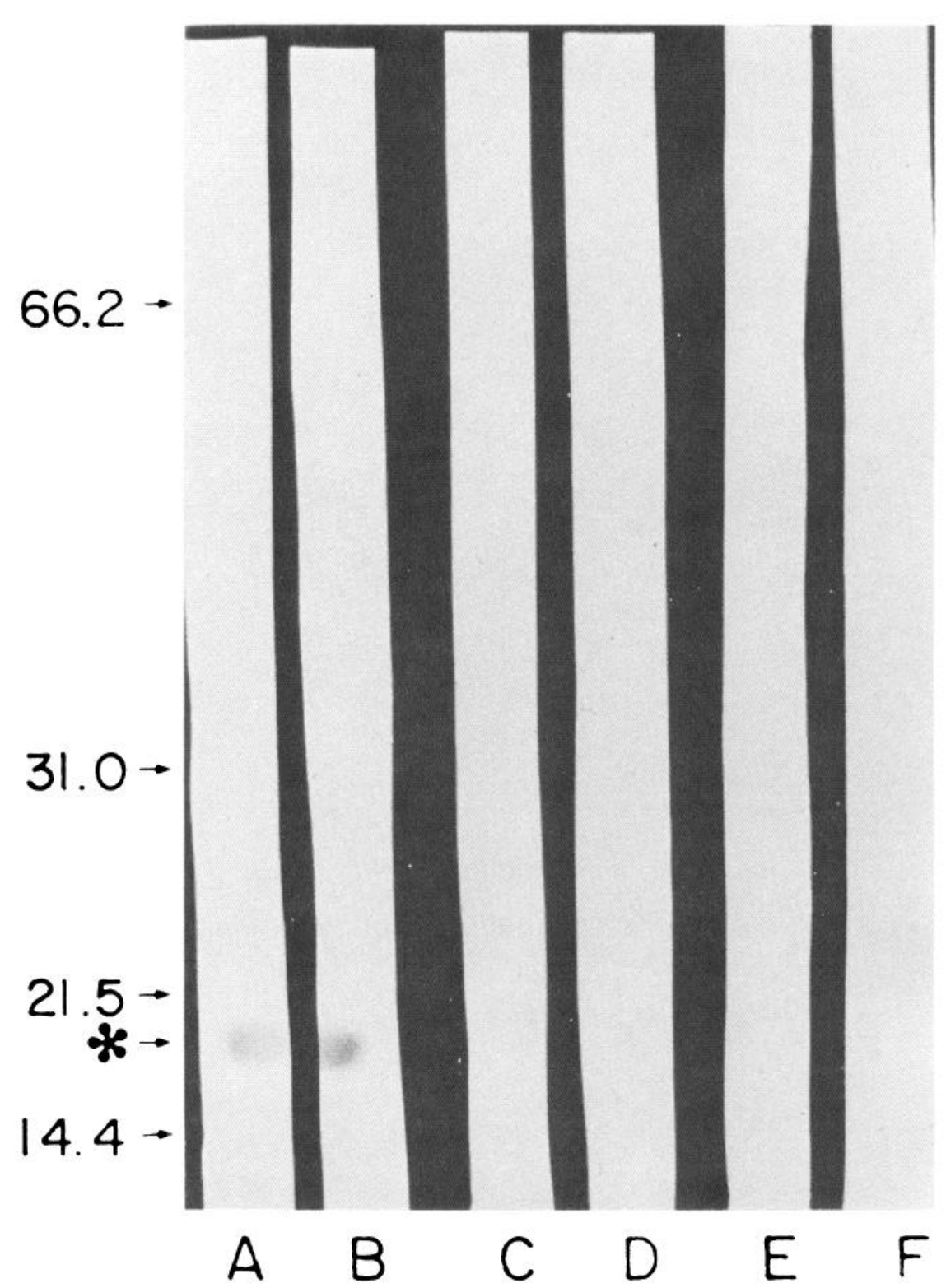

anti-MBP has been reported previously (Kennedy et al., 1980; Mirsky et al., 1980). Moreover, macrophage-microglia, which can phagocytose latex particles (Kennedy et al., 1980; Raff et al., 1979), did not bind any of the anti-MBP in their cytoplasm. This antibody seems to bind a different epitope from that of a recently described monoclonal antibody that binds to astrocytes and myelin sheaths but not to oligodendrocytes. That antibody does not bind to MBP in immunoblots (Dumas et al., 1985).

Thus, the anti-MBP M6C5 reacts with an astrocyte cytoplasmic constituent, although it is generally accepted that only the cells that produce myelin in CNS and in PNS (oligodendroglia and Schwann cells) contain MBP. It is therefore possible, but somewhat unlikely, that the M6C5 antibody binds to MBP in the astrocyte. It would seem, rather, to bind an epitope shared by MBP (oligodendrocytes and Schwann cells) and a non-MBP constituent of astrocytes that is not demonstrable in neurons, lymphocytes, fibroblasts, leptomeningeal cells, or monocytemacrophages with our current technology. The identity of this astrocyte constituent is not yet known. The sharing of this epitope between these particular cells of $\mathrm{CNS}$ origin may relate to a common neuroglial progenitor cell.

\section{References}

Abney, E. R., P. F. Bartlett, and M. C. Raff (1981) Astrocytes, ependymal cells and oligodendrocytes develop on schedule in dissociated cell cultures of embryonic rat brain. Dev. Biol. 83: 301-310.

Barbarese, E., and S. E. Pfieffer (1981) Developmental regulation of myelin basic protein in dispersed cultures. Proc. Natl. Acad. Sci. USA 78: 1953-1957.

Barbarese, E., P. E. Braun, and J. H. Carson (1977) Identification of prelarge and presmall basic proteins in mouse myelin and their structural relationship to large and small basic proteins. Proc. Natl. Acad. Sci. USA 74: 3360-3364.

Bignami, A., L. F. Eng, D. Dahl, and C. T. Uyeda (1972) Localization of the glial fibrillary acidic protein in astroyctes by immunofluorescence. Brain Res. 43: 429-435.

Bologa-Sandru, L., H. P. Siegrist, A. Z'graggen, K. Hopmann, U. Wiesmann, D. Dahl, and N. Herschkowitz (1981) Expression of antigenic markers during the development of oligodendrocytes in mouse brain cell cultures. Brain Res. 210: 217-229.

Bradford, M. M. (1976) A rapid and sensitive method for the quantitation of microgram quantities of protein utilizing the principle of protein-dye binding. Anal. Biochem. 72: 248-254.

Brockes, J. P., K. L. Fields, and M. C. Raff (1977) A surface antigenic marker for rat Schwann cells. Nature 266: 364-366. 
Carson, J. H., M. Nielson, and E. Barbarese (1980) In vitro translation of messenger RNA for myelin basic protein. Trans. Am. Soc. Neurochem. 11: 170 .

Davison, A. N., and A. Peters (1970) The Biochemistry of the Myelin Sheath. In Myelination, pp. 80-143, Thomas, Springfield, IL.

Deibler, G. E., R. E. Martenson, and M. W. Kies (1972) Large scale preparation of myelin basic protein from central nervous tissue of several mammalian species. Prep. Biochem. 2: 139-165.

Dumas, M., A. Zurbriggen, M. Vondevelde, S. H. Yim, B. G. W. Arnason, S. Shuzet, and C. Meier (1985) A monoclonal antibody that binds to both astrocytes and myelin sheaths. J. Neuroimmunol. 9: 55-67.

Dunkley, P. R., and P. R. Carnegie (1974) Amino acid sequence of the smaller basic protein from rat brain myelin. Biochem. J. 141: 243-255.

Eccleston, P. A., and D. H. Silberberg (1984) The differentiation of oligodendrocytes in a serum-free hormone supplemented medium. Dev. Brain Res. 16: 1-9.

Eisenbarth, G. S., F. S. Walsh, and M. Nirenberg (1979) Monoclonal antibody to a plasma membrane antigen of neurons. Proc. Natl. Acad. Sci. USA 76: 4913-4917.

Hirayama, M., D. H. Silberberg, R. P. Lisak, and D. E. Pleasure (1983) Long-term culture of oligodendrocytes isolated from rat corpus callosum by Percoll density gradient. J. Neuropathol. Exp. Neurol. 42: 16-28.

Kennedy, P. G. E., R. P. Lisak, and M. C. Raff (1980) Cell-typespecific markers for human glial and neuronal cells in culture. Lab. Invest. 43: 342-351.

Kennett, R. H., T. J. McKearn, and K. B. Bechtol (1982) Monoclonal Antibodies Hybridomas: A New Dimension in Biological Analyses, Plenum, New York.

Kim, S. U., J. Stern, M. W. Kim, and D. E. Pleasure (1983) Culture of purified rat astrocytes in serum-free medium supplemented with mitogen. Brain Res. 274: 79-86.

Kim, S. U., G. Maretto, B. Ruff, and D. H. Shin (1984) Culturc and cryopreservation of adult human oligodendrocytes and astrocytes. Acta Neuropathol. (Berl.) 64: 172-175.

Kreider, B. Q., A. Messing, H. Doan, S. U. Kim, R. P. Lisak, and D. E. Pleasure (1981) Enrichment of Schwann cell cultures from neonatal rat sciatic nerve by differential adhesion. Brain Res. 207: 433444.

Laemmli, V. K. (1970) Cleavage of structural proteins during the assembly of the head of bacteriophage Ty. Nature 227: 680-685.

Lee, V., H. L. Wu, and W. W. Schlaepfer (1982) Monoclonal antibodies recognize individual neurofilament triplet proteins. Proc. Natl. Acad. Sci. USA 79: 6089-6092.

Lisak, R. P., M. Hirayama, D. Kuchmy, A. Rosenzweig, S. U. Kim, D. E. Pleasure, and D. H. Silberberg (1983) Cultured human and rat oligodendrocytes and rat Schwann cells do not have immune response gene associated antigens (Ia) on their surface. Brain Res. 283: 285292.

Martenson, R. E., G. E. Deibler, M. W. Kies, S. S. McNeally, R. Shapira, and R. F. Kibler (1972) Differences between the two myelin basic proteins of the rat central nervous system: A deletion in the smaller protein. Biochem. Biophys. Acta 263: 193-203.

Mirsky, R., J. Winter, E. Abney, R. Pruss, J. Gavrilovic, and M. C. Raff (1980) Myelin specific proteins and glycolipids in rat Schwann cells and oligodendrocytes in culture. J. Cell Biol. 84: 483-494.

Norton, W. T., and S. Poduslo (1973) Myelination in rat brain: Methods of myelin isolation. J. Neurochem. 21: 749-757.

Raff, M. C., R. Mirsky, K. Fields, R. P. Lisak, S. Dorfman, D. H. Silberberg, N. A. Gregson, S. Leibewitz, and M. C. Kennedy (1978) Galactocerebroside is a specific cell surface antigenic marker for oligodendrocytes in culture. Nature 274: 813-816.

Raff, M. C., K. L. Fields, S. Hakomori, R. Mirsky, R. M. Pruss, and J. Winter (1979) Cell-type specific markers for distinguishing and studying neurons and the major classes of glial cells in culture. Brain Res. 174: 283-308.

Raff, M. C., E. A. Abney, J. Cohen, R. Lindsay, and M. Noble (1983a) Two types of astrocytes in cultures of developing rat white matter: Differences in morphology, surface gangliosides and growth characteristics. J. Neurosci. 3: 1289-1300.

Raff, M. C., R. H. Miller, and M. Noble (1983b) A glial progenitor cell that develops in vitro into an astrocyte or an oligodendrocyte depending on the culture medium. Nature 303: 390-396.

Roussel, G., G. Labourdette, and J. Nussbaum (1981) Characterization of oligodendrocytes in primary cultures from brain hemispheres of newborn rats. Dev. Biol. 81: 372-378.

Sternberger, N. H., Y. Itoyama, M. W. Kies, and H. de F. Webster (1978) Myelin basic protein demonstrated immunocytochemically in oligodendroglia prior to myelin sheath formation. Proc. Natl. Acad. Sci. USA 75: 2521-2524.

Sternberger, N. H., C. del Cerro, M. W. Kies, and R. M. Herndon (1985) Immunocytochemistry of myelin basic proteins in adult rat oligodendroglia. J. Neuroimmunol. 7: 355-363.

Suzumura, A., S. Bhatt, P. A. Eccelston, R. P. Lisak, and D. H. Silberberg (1984) The isolation and long-term culture of oligodendrocytes from newborn mouse brain. Brain Res. 324: 379-383.

Temple, S., and M. C. Raff (1985) Differentiation of a biopotential glial progenitor cell in a single cell microculture. Nature 313: 223225 .

Ternynck, T., and S. Avrameas (1976) Polymerization and immobilization of proteins using ethylchloroformate and glutaraldehyde. In Immunoadsorbents in Protein Purification, E. Ruoslahti, ed., pp. 2935, University Park Press, Baltimore. 